\title{
BEST PRACTICE PERANCANGAN FASILITAS BANGUNAN DAN DATA CENTER LAYOUT BERDASARKAN TIERING LEVEL STANDAR TIA-942 DENGAN METODE PPDIOO DI PEMERINTAH KABUPATEN BANDUNG
}

\section{BEST PRACTICE DESIGN BUILDING FACILITIES AND DATA CENTER LAYOUT BASED ON TIERING LEVEL OF TIA-942 STANDARD USING PPDIOO METHOD IN PEMERINTAH KABUPATEN BANDUNG}

\author{
${ }^{1}$ Febryan Elfanuary A., ${ }^{2}$ Rd. Rohmat Saedudin, ${ }^{3}$ Umar Y.K.S. Hediyanto \\ 1,2,3Program Studi Sistem Informasi, Fakultas Rekayasa Industri, Telkom University \\ elfanuaryfebryan@gmail.com ${ }^{1}$,rdrohmat@telkomuniversity.ac.id ${ }^{2}$, umaryunan@telkomuniversity.ac.id ${ }^{3}$
}

\begin{abstract}
Abstrak - Pemerintah Kabupaten Bandung merupakan salah satu badan struktural pemerintahan yang mengurus keperluan masyarakat di wilayah Kabupaten Bandung, Provinsi Jawa Barat. Berdasarkan Rencana Jangka Panjang Pemerintah Kabupaten Bandung periode 2016-2020, akan dilakukan pengembangan ruang server menjadi data center pada Dinas Komunikasi, Informatika, dan Statistik. Oleh karena itu, dibutuhkan perancangan data center terkait fasilitas bangunan dan layout yang termasuk kebutuhan ruangan data center, sistem layout rak, dan sistem pengkabelan sebagai dasar untuk membantu dalam melakukan pengembangan yang mengacu pada Standar TIA-942. Dalam perancangan fasilitas bangunan dan data center layout ini, menggunakan metode PPDIOO Network Life-Cycle Approach dengan tiga tahapan, yaitu prepare, plan, dan design. Metode ini dipilih karena cocok dalam hal perancangan awal infrastruktur, memiliki cycle pada tahapnya, dan terdapat tahap optimize untuk pengembangan jangka panjang. Hasil akhir dari penelitian ini adalah rancangan usulan fasilitas bangunan dan data center layout untuk Pemerintah Kabupaten Bandung meliputi kebutuhan ruangan, sistem layout rak, dan sistem pengkabelan yang sesuai dengan Standar TIA942
\end{abstract}

Kata kunci-Data center, TIA-942 standard, PPDIOO life-cycle approach, Ruangan data center, Sistem layout rak, Sistem pengkabelan.

Abstract - Pemerintah Kabupaten Bandung is one of the government structural agency that manages all the needs of people in Bandung regency, West Java Province. Based on the long term plan of Pemerintah Kabupaten Bandung period 2016-2020, there will be a development of a server room into a data center in Dinas Komunikasi, Informatika, dan Statistik. Therefore it's necessary to design a data center related to building facilities and layout. The design includes data center room needs, rack layout system, and cabling system as a basis to assist in doing development which refers to TIA-942 Standard. In the designing of building facilities and data center layout, PPDIOO network life-cycle approach method is used with three stages as follows: prepare, plan, and design. This method is suitable in terms of initial design the infrastructure, it has a cycle at it's stages, and there is an optimizing

$\begin{array}{ll}\text { Sejarah artikel } & \\ \text { Diterima redaksi: } & : 19 \text { Mei } 2017 \\ \text { Revisi akhir } & : 22 \text { Oktober } 2017 \\ \text { Diterbitkan online } & : 29 \text { Desember } 2017\end{array}$

stage for long-term development. The final result of this reseacrh is the building facilities and data center layout plan for Pemerintah Kabupaten Bandung includes room needs, rack layout system, wiring system which according to TIA-942 Standard.

Keywords - Data center, TIA-942 standard, PPDIOO life-cycle approach, Data center rooms, Rack layout system, Cabling system.

\section{PENDAHULUAN}

Perkembangan dan penggunaan Teknologi Informasi (TI) pada era sekarang ini sudah menjadi sebuah kebutuhan utama, sehingga terciptalah konvergensi TI yang sudah menjadi fenomena umum saat ini [1]. Produk dari perkembangan TI ini salah satu diantaranya adalah data center yang merupakan lingkungan fasilitas fisik yang dirancang untuk sistem perumahan komputer dan komponenkomponen lainnya yang saling berkaitan. Di dalamnya berisi peralatan teknologi informasi dan komunikasi serta fasilitas pendukungnya, seperti sekumpulan peralatan elektronik utama yang digunakan untuk memproses data yaitu server, penyimpanan data yaitu peralatan penyimpanan, dan komunikasi yaitu peralatan jaringan. Secara bersamaan, peralatan-peralatan ini memproses, menyimpan, dan mentransmisikan informasi digital [2].

Dalam perancangan data center ada beberapa aspek yang harus diperhatikan sesuai standar yang ada, dalam hal ini Telecommunications Industry Association (TIA) bekerjasama dengan Electronic Industry Association (EIA), suatu organisasi terpisah yang diakui oleh American National Standard Institue (ANSI) telah membuat standardisasi perancangan infrastruktur data center yang telah diakui secara internasional, yaitu Standar TIA-942 [3].

Pemerintah Kabupaten Bandung merupakan suatu badan struktural pemerintah yang mengurus segala keperluan masyarakat yang berada di wilayah Kabupaten Bandung, Provinsi Jawa Barat. Terdapat Dinas Komunikasi, Informatika dan Statisik di dalamnya yang menangani seluruh Sistem Informasi Manajemen (SIM) yang 
digunakan pada Pemerintah Kabupaten Bandung. Dimana seluruh SIM ini dapat diakses melalui Internet yang berpusat di data center yang dikelola oleh Dinas Komunikasi, Informatika dan Statistik [4]. Berdasarkan observasi pengembangan ruang server menjadi data center pada Pemerintah Kabupaten Bandung khususnya pada bagian infrastruktur masih belum optimal karena belum mengacu pada suatu standar, padahal hal ini sangat penting dilakukan agar Dinas Komunikasi, Informatika dan Statistik dapat melakukan tugasnya dengan baik dengan layanan pendukung yang memadai. Karena hal tersebut maka perlu dilakukan analisis terhadap pembangunan fasilitas bangunan dan data center layout pada Pemerintah Kabupaten Bandung berdasarkan tiering level Standar TIA-942 yang disesuaikan dengan kebutuhan untuk mengoptimalisasikan pengembangan data.

\section{STUDILITERATUR}

\section{A. Data center}

Berdasarkan salah satu buku standardisasi untuk data center yang dikeluarkan Telecommunications Industry Association, definisi data center merupakan sebuah bangunan atau bagian dari suatu bangunan untuk menempatkan ruang komputer dan area-area lain sebagai pendukungnya. Fungsi utamanya adalah mengkonsolidasi dan memusatkan seluruh sumber daya teknologi informasi, tempat dari operasional jaringan, sebagai fasilitas untuk bisnis elektronik, dan juga untuk memberikan layanan untuk operasi pengolahan data yang penting [5].

\section{Layanan utama data center}

Ada beberapa layanan utama yang secara umum merupakan keluaran dari data center yang digambarkan pada Gambar 1, yaitu: Business continuance infrastructure, data center security infrastructure, application optimization, IP infrastructure, dan storage infrastructure.

\section{Kriteria data center}

Data center dibangun karena memiliki tujuan yang harus dicapai, yaitu terpenuhinya kriteria-kriteria pada data center, yaitu: 1) Availability; 2) Flexibility and Scalability; dan 3) Security

\section{B. TIA-942 standard}

Standar TIA-942 adalah standar internasional yang dikeluarkan oleh Telecommunication Industry Association untuk menentukan persyaratan minimum rancangan infrastruktur telekomunikasi pada data center dan ruang komputer, termasuk data center yang dimiliki oleh satu perusahaan maupun data center yang dimiliki bersama oleh lebih dari satu perusahaan. Standar ini pertama kali diterbitkan pada tahun 2005 yang bernama TIA/EIA-568 yang membahas tentang struktur pengkabelan dan diperbaharui pada April 2012 menjadi ANSI/TIA-942. Ada beberapa kunci elemen-elemen pada Standar TIA-942 sebagai alat yang berharga dalam proses awal perancangan data center. Adapun elemen-elemen tersebut, yaitu site space and layout, cabling infrastructure, tiered reliability, dan environmental considerations [6].

\section{Site space and layout}

Mengalokasikan ruang yang tepat untuk data center dimulai dengan memastikan ruang mana yang dapat dengan mudah mengikuti perubahan dan pertumbuhan kebutuhan pada masa yang akan datang. Data center harus dirancang dengan banyak "white space", yaitu ruang kosong yang dapat menampung rak pada masa yang akan datang. Untuk mendapatkan kinerja yang optimal, data center perlu dilengkapi dengan beberapa ruang pendukung diantaranya:

a. Server room, ruangan dimana semua perangkat jaringan dan komputer yang terkait saling bekerja dan mengolah, menyediakan, menyimpan, serta menyalurkan data.

b. Electrical \& mechanical room, ruangan dimana lokasi kebutuhan yang berkaitan dengan kebutuhan listrik yang digunakan pada data center, dan penyimpanan peralatan pendukung.

c. Operation command center, ruangan dimana administrator atau karyawan memantau seluruh perangkat yang terpasang dan juga segala aktivitas yang ada di dalam data center.

d. Entrance room, merupakan area terpusat tempat dimana semua struktruk kabel data bagian internal berakhir.

e. Loading dock \& storage room, merupakan tempat untuk menerima peralatan yang baru datang dari vendor untuk masuk ke data center dan sebagai tempat penyimpanan persediaan peralatan yang dibutuhkan pada data center.

f. Staging \& backup room, merupakan tempat administrator, network engineer, dan vendor untuk mengkonfigurasi atau membangun peralatan dan ruangan ini bersifat opsional.

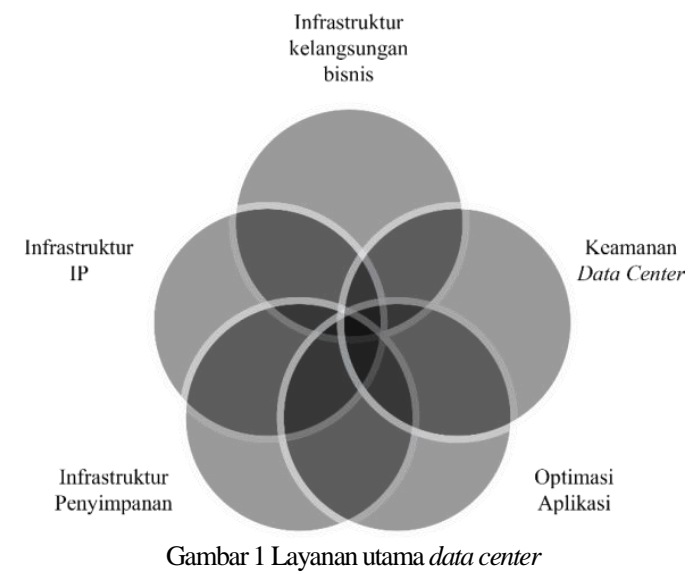

2. Cabling infrastructure

Standar TIA-942 sudah menetapkan spesifikasi umum untuk sistem pengkabelan telekomunikasi dan memberikan spesifikasi untuk media kabel yang digunakannya seperti: Standar single mode fiber, 62.5 dan $50 \mu \mathrm{m}$ multi mode fiber, $75 \mathrm{ohm}$ coaxial cable, dan 4pair category 6 UTP. Pada infrastruktur pengkabelan ada beberapa area fungsional yang nantinya menjadi jalur pengkabelan yang tergambar pada Gambar 2, yaitu:
a. Entrance room
b. Main distribution area
c. Horizontal distribution area
d. Equipment distribution area
e. Zone distribution area 
Pemisahan kabel listrik dan kabel telekomunikasi atau data dilakukan untuk menghindari terjadinya interferensi elektromagnetik dari kabel listrik dan juga mengakomodasi banyaknya perangkat yang terdapat di data center. Umumnya kabel fiber dan twisted-pair pada cable tray sebaiknya dipisahkan sehingga dapat meningkatkan efisiensi kegiatan penelusuran dalam operasional. Perlu diingat jika hal ini dilakukan maka kabel fiber umumnya berada di atas kabel twisted-pair [7]. Cable tray merupakan suatu alat yang digunakan untuk penempatan jalur kabel pada data center. Penggunaan cable tray terbagi menjadi dua jenis, yaitu: overhead cable tray yang dapat mengurangi penggunaan raised floor pada data center yang tidak memungkinkan menggunakan raised floor untuk melakukan pengkabelan di bawahnya dan cable tray yang diletakan di bawah raised floor.
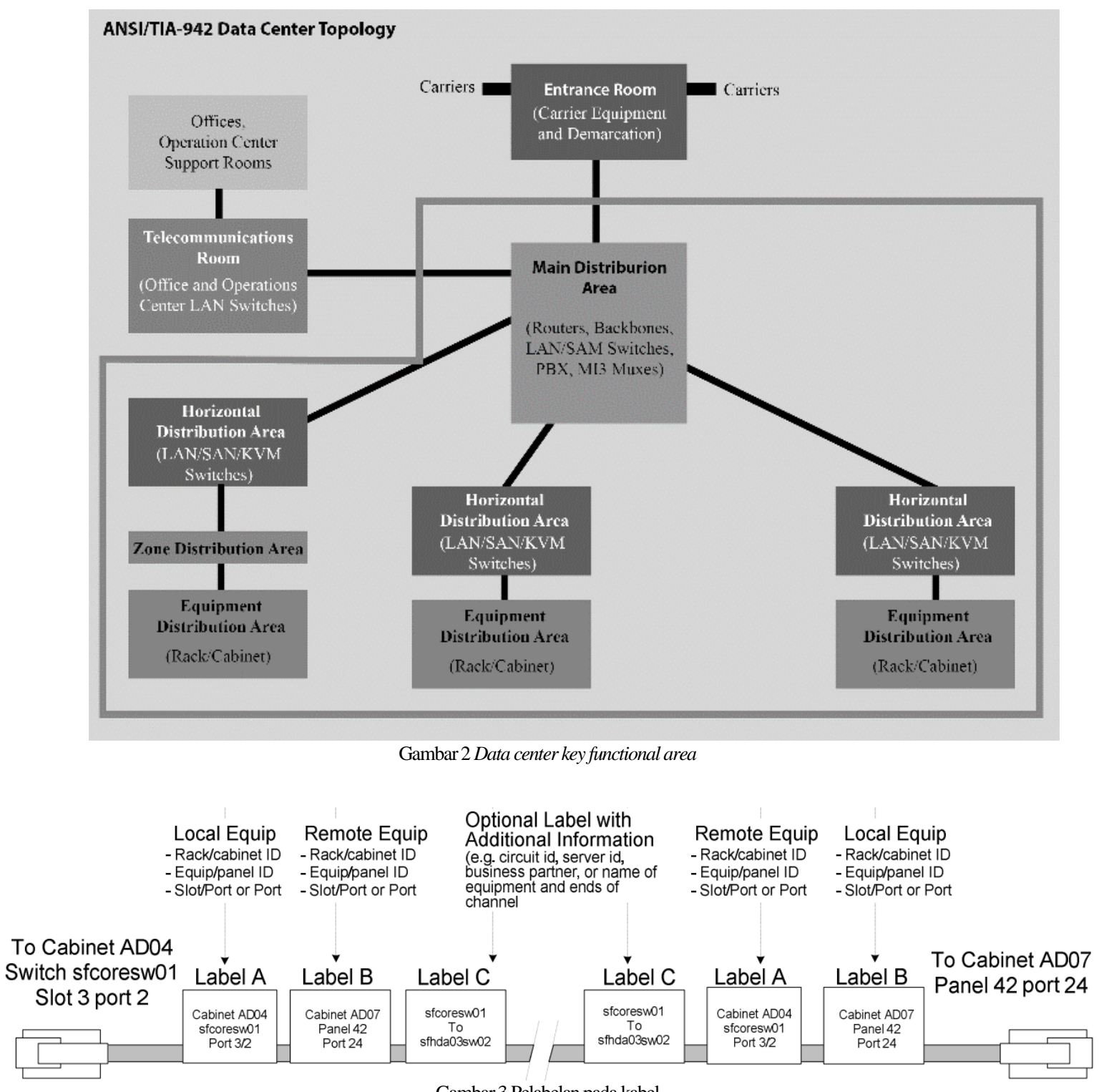

Gambar 3 Pelabelan pada kabel

Pelabelan pada kabel dapat dilakukan pada setiap ujung darì suatu kabel untuk mengidentifikasi perangkat atau patch panel pada kedua ujungnya. Label yang paling dekat dengan konektor berfungsi mengidentifikasi perangkat dimana kabel tersebut di pasang, label berikutnya mengidentifikasi perangkat pada ujung kabel yang satunya lagi dipasang. Label ini harus berisi informasi seperti pada Gambar 3 [8] yaitu: 1) Identitas rak atau kabinet; 2) Identitas perangkat atau patch panel; dan Nomor port pada perangkat

\section{Tiered reliability}

Standar ini memberikan juga penjelasan tingkatan-tingkatan mengenai penentuan kebutuhan data center secara spesifik yang sudah disesuaikan dengan informasi dari Uptime Institute [9]. Pada masing-masing keempat tingkatan ini sudah menjelaskan secara rinci mengenai arsitektur, kelistrikan, hal-hal mekanis, dan rekomendasi telekomunikasi. Semakin tinggi tingkatannya maka semakin tinggi juga tingkat ketersediaan layanannya yang dirangkum pada Tabel 1 . 
TABEL 1

TIERINGLEVEL SPECIFICATION

\begin{tabular}{|c|c|c|c|c|}
\hline Tier & Redundant & $\begin{array}{l}\text { Implement- } \\
\text { ation }\end{array}$ & $\begin{array}{c}\text { Annual } \\
\text { downtime }\end{array}$ & Availability \\
\hline I - Basic & $\mathrm{N}$ & 3 Month & $\begin{array}{l}28.8 \text { Hour } \\
\text { in year }\end{array}$ & $99.671 \%$ \\
\hline $\begin{array}{c}\text { II-Redundant } \\
\text { Components }\end{array}$ & $\mathrm{N}+1$ & 3-6 Month & $\begin{array}{l}22 \text { Hour in } \\
\text { year }\end{array}$ & $99.741 \%$ \\
\hline $\begin{array}{c}\text { III- } \\
\text { Concurrently } \\
\text { Maintainable }\end{array}$ & $\mathrm{N}(\mathrm{N}+1)$ & 15-20 Month & $\begin{array}{c}\text { 1.6 Hour in } \\
\text { year }\end{array}$ & $99.982 \%$ \\
\hline $\begin{array}{c}\text { IV - Fault } \\
\text { Tolerant }\end{array}$ & $(2(\mathrm{~N}+1))$ & 15-20 Month & $\begin{array}{c}0.4 \text { Hour in } \\
\text { year }\end{array}$ & $99.995 \%$ \\
\hline
\end{tabular}

4. Environmental considerations

Pertimbangan lingkungan yang harus diperhatikan terkait pembangunan data center secara umum sudah tercantum dalam Standar TIA-942 beberapa diantaranya:

a. Bangunan harus mematuhi semua aturan yang berlaku secara nasional, negara bagian, dan daerah lokal.

b. Pertimbangan harus diberikan untuk penentuan letak geografis.

c. Pertimbangan harus diberikan untuk peraturan zonanisasi dan hukum penggunaan lahan sekitar.

\section{Rack layout system}

Rack layout system merupakan suatu sistem yang digunakan untuk menempatkan server maupun perangkat jaringan dalam suatu kesatuan rak. Tujuan dari racking ini adalah untuk mengurangi tempat atau ruang yang digunakan oleh perangkat jaringan dan merapikan perangkat jaringan yang tersambung oleh sistem pengkabelan sehingga tidak berantakan dan terkumpul dalam satu tempat. Setiap konfigurasi rak harus mencerminkan kebutuhan daya keseluruhan dan beban yang akan ditanggung. Dalam pengaturan rak dibutuhkan keselarasan untuk memisahkan udara panas dan udara dingin. Rak harus diatur dalam pola bolak-balik atau saling membelakangi maupun berhadapan, dengan pola tersebut maka akan terciptanya hot aisle sebagai area mengalirnya udara panasa dan cold aisle sebagai area mengalirnya udara dingin. Cold aisle berada di bagian depan rak, sedangkan hot aisle berada di bagian belakang rak seperti pada Gambar 4. Rak memiliki beberapa slot yang dapat dimasuki oleh perangkat jaringan yang dinamakan rack unit. Rak dapat dikelompokan menjadi beberapa kelompok berdasarkan perangkat atau kegunaan dari perangkat yang ada di dalam rak tersebut, yaitu: 1) Network rack; 2) Server rack; 3) Patching rack. Sedangakan berdasarkan jenisnya terbagi menjadi beberapa jenis yaitu closed rack, open rack, containment rack [10].

Pelabelan pada rak juga perlu diperhatikan, terdapat dua metode pelabelan rak yaitu, dengan menggunakan grid dan kedua berdasarkan baris yang biasanya pada ruangan tidak terdapat grid khusus sehingga, penomoran rak hanya diurutkan berdasarkan baris sesuai jumlah baris rak-rak yang ada [8].

\section{PPDIOO network life-cycle approach}

PPDIOO merupakan metode analisis sampai pengembangan instalasi jaringan komputer yang dikembangkan oleh Cisco pada materi yang berjudul Designing for Cisco Internetwork Solution yang mendefinisikan siklus hidup layanan yang dibutuhkan untuk melakukan pengembangan jaringan komputer atau teknologi terkait. Terdapat 6 tahapan pada metode seperti pada Gambar 5. [11]

\section{METODE PENELITIAN}

Penelitian ini menggunakan metode PPDIOO Network LifeCycle Approach.

\section{A. Model konseptual}

Model ini menggambarkan kerangka penelitian tugas akhir perancangan fasilitas bangunan dan data center layout berdasarkan tiering level pada Pemerintah Kabupaten Bandung yang bertujuan untuk membuat desain sistem pengkabelan listrik \& data, denah ruangan, dan rack layout system pada data center yang sesuai dengan Standar TIA-942.

Pada Gambar 6 dapat dijelaskan bahwa penelitian ini bertujuan membangun suatu artefak berupa desain fasilitas bangunan dan data center layout pada Pemerintah Kabupaten Bandung yang sesuai dengan Standar TIA-942. Artefak ini muncul dari hasil evaluasi dengan melakukan analisis terhadap kondisi saat ini pada ruang server Pemerintah Kabupaten Bandung. Dalam menganalisis objek yang akan diteliti perlu adanya pertimbangan dari masalah yang timbul dalam lingkungan objek yang akan diteliti seperti data center yang ada pada Pemerintah Kabupaten Bandung masih dalam kondisi standar yang sangat minim, serta tidak meratanya kemampuan user dalam pengelolaan data center. Selain itu, perlu adanya pertimbangan dari dasar ilmu yang digunakan. Dalam hal ini Standar TIA-942, teori terkait best practice perancangan data center digunakan sebagai suatu acuan, dan penggunaan metodologi yang cocok untuk penetilian ini, yaitu PPDIOO dengan hanya menggunakan tahap prepare, plan, dan design di dalamnya.

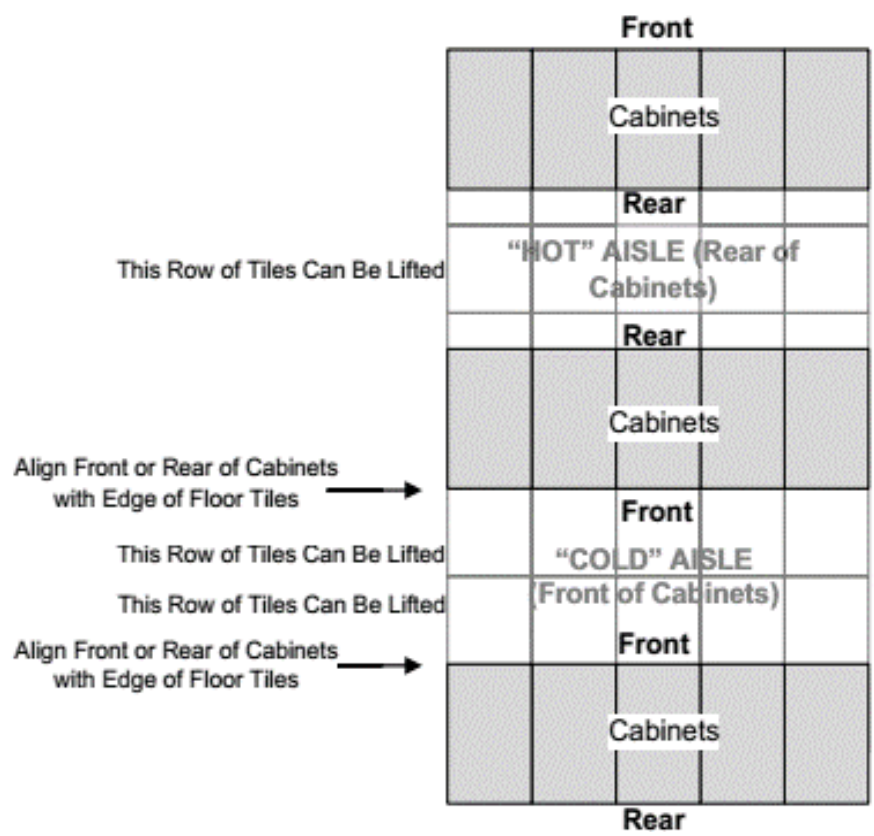

Gambar 4 Rack layout system 


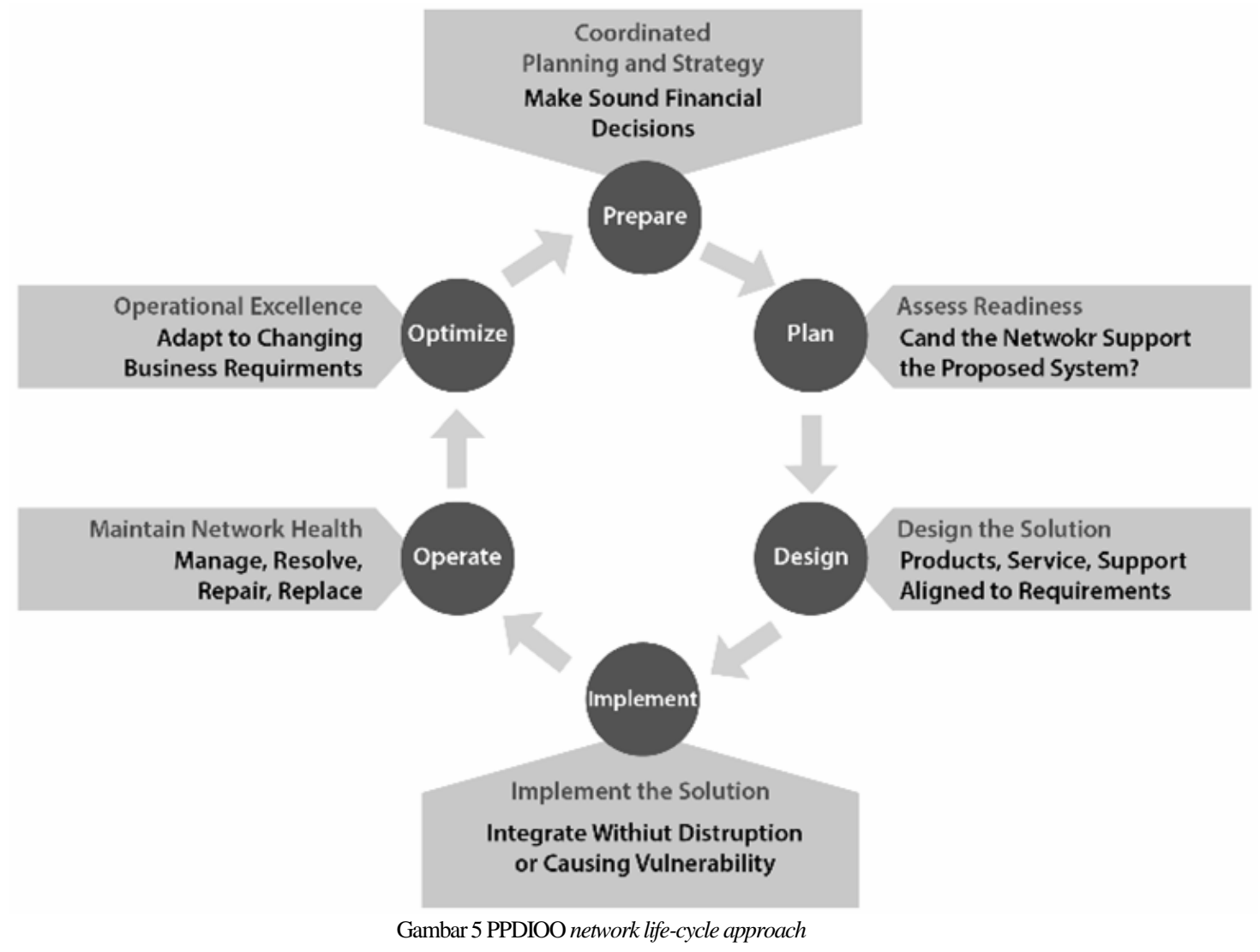

\section{HASILDAN ANALISIS}

A. Kondisi ruangan dan rak pada data center saat ini

Data center Pemerintah Kabupaten Bandung berada pada Dinas Komunikasi, Informatika, dan Statistik. Ruangan data center hanya memiliki satu ruang server dengan ukuran $2.895 \mathrm{~m}$ x $9.84 \mathrm{~m}$ yang berisi dua rak dengan spesfikasi $42 \mathrm{U}$, terdapat 1 unit $\mathrm{AC}$ split, dan 1 unit UPS yang tergambar pada Lampiran 1 .

B. Kondisi rack layout system pada data center saat ini

Dalam Pengamatan yang dilakukan pada data center Pemerintah Kabupaten Bandung sesuai Lampiran 1, pengaturan tata letak rak masih belum meggunakan metode apapun berdasarkan standar yang ada. Sehingga tidak memungkinkan untuk melakukan pengembangan dalam penambahan rak nantinya. Selain itu, belum adanya pelabelan pada rak, perangkat dan juga port pada perangkat yang berfungsi untuk melakukan identifikasi.

\section{Kondisi pengkabelan pada data center saat ini}

Dalam pengamatan yang dilakukan pada data center Pemerintah Kabupaten Bandung, sistem pengkabelan listrik dan data masih dalam satu jalur yang sama. Selain itu sistem pengkabelan juga belum menggunakan cable tray yang tergambar pada Lampiran 2.
D. Denah ruangan usulan tier 1 , tier 2 , dan tier 3

Pada tier 1 data center Pemerintah Kabupaten Bandung membutuhkan ruang entrance sebagai ruang sterilisasi sebelum memasuki ruang server. Selanjutnya, ruang electrical \& mechanical sebagai ruang penyimpanan peralatan kelistrikan seperti main distribution panel, UPS, dan juga sebagai tempat meletakan peralatan terkait fire suppression system. Selanjutnya, ruang storage \& loading dock sebagai area keluar masuknya barang-barang dan juga sebagai tempat penyimpanan barang yang dibutuhkan untuk data center. Selain itu, terdapat ruang generator sebagai ruang meletakan generator yang berperan sebagai cadangan power supply. Ruangan-ruangan tersebut adalah ruangan pendukung dari ruang server agar data center dapat berjalan secara optimal. Pada tier 2 ruangan yang dibutuhkan, yaitu ruang operation center yang berfungsi sebagai ruang kontrol dan pemantauan ruang server serta segala aktivitas yang ada pada data center. Dalam denah usulan ruang operation center ini menggantikan fungsi ruang kerja staff operasional Dinas Komunikasi, Informatika, dan Statistik Pemerintah Kabupaten Bandung seperti yang tergambar pada Lampiran 3. Berdasarkan Lampiran 4 pada tier 3 data center membutuhkan redundansi ruang entrance agar memudahkan akses masuk ke dalam ruang server jika terjadi masalah terkait akses dari salah satu ruang entrance atau bisa digunakan sebagai jalur masuk sekunder khusus bagi pihak vendor. Selain itu, ruang generator harus sudah terpisah dari gedung data center karena generator pada tier 3 harus sudah memiliki redundansi serta agar terhindar dari efek terjadinya polusi suara ke dalam gedung data center. 


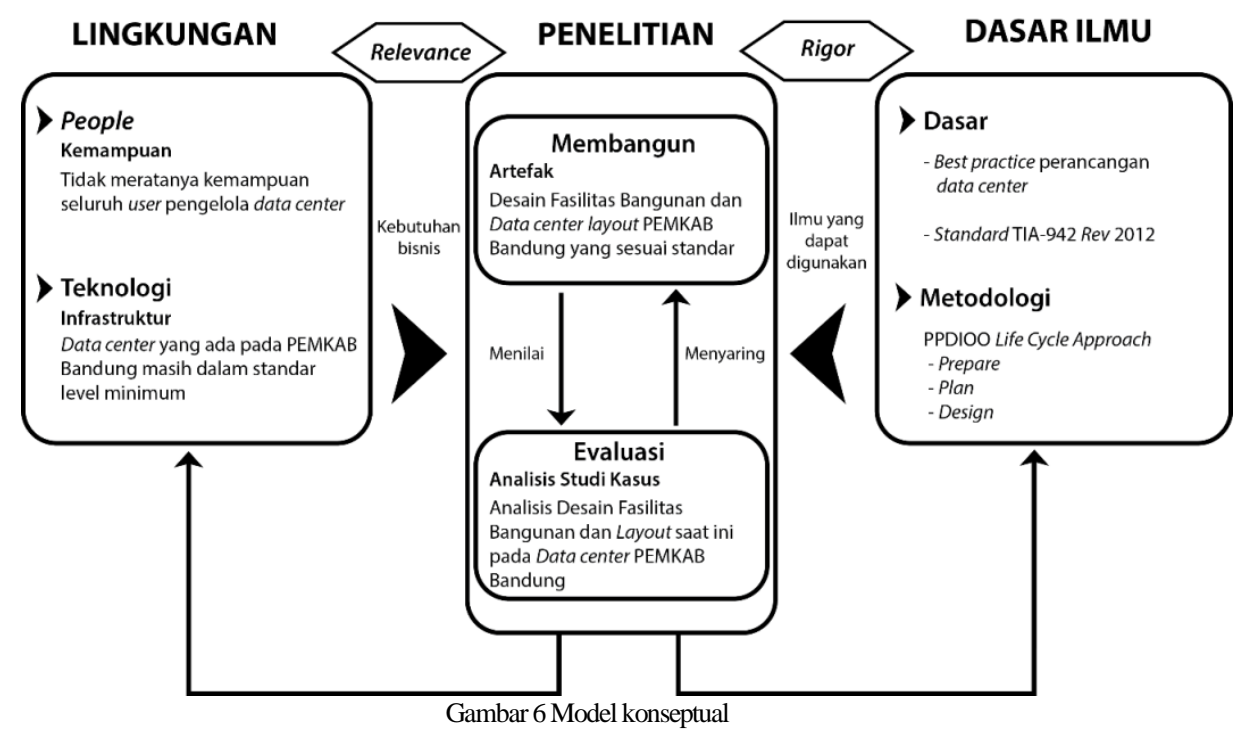

E. Denah rack layout system usulan tier 1, tier 2, dan tier 3

Pada tier 1 dalam pengaturan sistem rak membutuhkan tata letak yang dapat menciptakan aisle di depan dan di belakang barisan rak yang berfungsi sebagai alur udara panas dan udara dingin. Selain itu, dalam meletakan sebuah rak di atas raised floor harus dipastikan agar raised floor yang berada tepat di depan atau di belakang rak dapat diangkat untuk memudahkan pengecekan maupun pengkonfigurasian peralatan yang ada di bawah raised floor, pengelompokan rak berdasarkan jenis perangkat yang ada di dalamnya, serta pemberian jarak $1 \mathrm{U}$ (unit) rak antar perangkat dalam rak. Dalam hal pelabelan rak menggunakan metode baris dan pelabelan perangkat yang ada di dalam rak harus berdasarkan nomor unit yang ada pada rak agar memudahkan user untuk melakukan pencarian dan pemeliharaan seperti yang tergambar pada Gambar 7 dan Error! Reference source not found.. Pada tier 2 dan 3 yang dibutuhkan adalah redundansi power supply untuk perangkat yang ada di dalam rak, dengan sudah adanya usulan generator pada tier 2 dan 3 maka redundansi ini sudah terpenuhi dalam usulan sesuai pada Lampiran 4.

F. Denah sistem pengkabelan usulan tier 1, tier 2, dan tier 3

Berdasarkan denah usulan tier 3 pada Lampiran 4 yang dapat mewakili denah tier 1 dan tier 2, sudah memenuhi pemisahan kabel listrik yang menggunakan cable tray yang diletakan di bawah raised floor dan kabel data menggunakan overhead cable tray yang diletakan pada atap ruang server tepat di atas rak. Selain itu, peletakan overhead cable tray sudah terpisah dari lampu dan peralatan pendukung lainnya seperti smoke detector dan nozzle. Selanjutnya, untuk pelabelan kabel harus memiliki tiga identitas pada tiap ujungnya terdiri dari label A yang menjelaskan identitas perangkat asal atau dimana ujung kabel tersebut dipasang pada port perangkat sumber, label B menjelaskan identitas perangkat tujuan atau dimana kabel tersebut terhubung ke perangkat tujuannya, dan label C menjelaskan informasi tambahan yang menjelaskan fungsi dari koneksi antar keterkaitan setiap perangkat melalui kabel tersebut yang terdapat pada Gambar 9. Pada tier 2 hanya terdapat perbedaan bahwa patch cord harus sudah diberi label juga sesuai metode pelabelan yang diterapkan pada tier 1 .

Berdasarkan Lampiran 4, entrance area pada tier 3 merupakan area dimana kabel backbone yang diwakilkan dengan garis kuning sebagai kabel utama yang masuk ke ruang server dan datang dari ruang entrance. Area ini sudah memiliki redundansi sehingga data center Pemerintah Kabupaten Bandung harus memiliki lebih dari satu sumber ISP (Internet Service Provider). Pada tier 3 data center harus memiliki dokumentasi terkait pelabelan rak, perangkat, dan kabel yang sudah diterapkan.
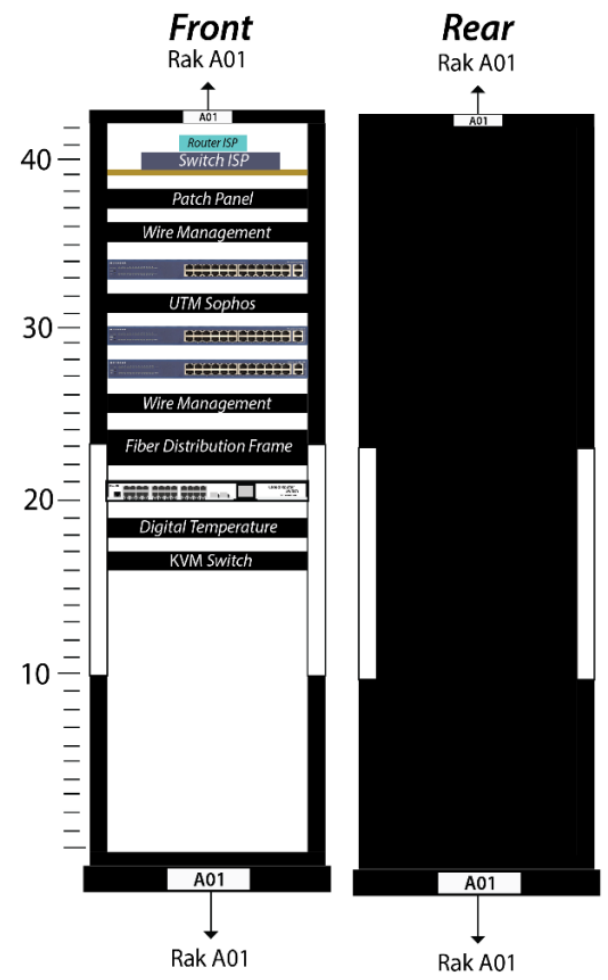

Gambar 7 Pelabelan pada rak 


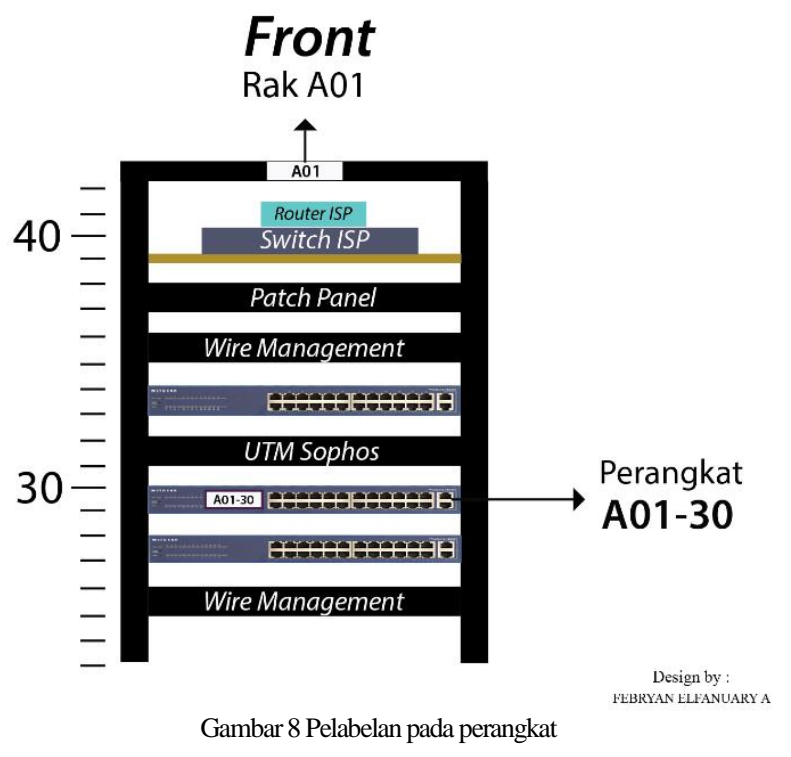

V. KESIMPULAN

Berdasarkan penelitian yang telah dilakukan dapat ditarik kesimpulan bahwa data center masih belum memiliki ruang-ruang pendukung untuk ruang server sesuai Standar TIA-942, pengaturan rak pada ruang server masih belum menggunakan metode sesuai Standar TIA-942 sehingga dapat menyebabkan keterhambatan dalam melakukan pengembangan, penerapan pelabelan pada rak, kabel dan perangkat belum dilakukan dan tentu juga belum memenuhi Standar TIA-942. Peletakan kabel-kabel pada data center belum menggunakan cable tray, Pengaturan dalam peletakan kabel listrik dan kabel data masih dalam satu jalur dan belum sesuai dengan Standar TIA-942, ruang server pada data center belum memiliki redundansi kabel backbone dan entrance area untuk tier 3.
Selain itu, pada data center Pemerintah Kabupaten Bandung belum memiliki dokumentasi terkait pelabelan rak, kabel, dan perangkat.

Sehingga penelitian ini menghasilkan rancangan data center untuk Pemerintah Kabupaten Bandung yang memiliki ruangan pendukung untuk ruang server seperti mechanical \& electrical room yang sebelumnya merupakan ruangan kosong. Selanjutnya, loading dock \& storage room yang terbentuk dari hasil pemberian sekat pada ruang server. Selain itu, ruang kerja yang terdapat di sebelah ruang server berubah fungsinya menjadi ruang operation center, dan generator room yang dibangun di sebelah ruang mechanical \& electrical room untuk tier 1 sampai 2. Sedangkan untuk tier 3 ruang generator sudah terpisah dari gedung data center, dan entrance room pada tier 1 dan 2 terbentuk dari hasil pemberian sekat pada ruang operation center, sedangkan pada tier 3 terdapat redundansi entrance room yang terletak di sebelah loading dock \& storage room.

Pengaturan tata letak rak menggunakan metode berdasarkan baris sesuai dengan Standar TIA-942 sehingga memungkinkan dilakukannya pengembangan lebih lanjut sesuai Rencana Jangka Panjang Pemerintah Kabupaten Bandung. Kemudian pelabelan rak, perangkat, dan kabel sudah sesuai dengan Standar TIA-942. Rak sudah memiliki label di bagian depan dan di bagian belakang rak yang sesuai dengan baris. Perangkat sudah memiliki label yang sesuai dengan satuan unit dalam rak. Kabel sudah memiliki tiga label yang menjelaskan asal perangkat, tujuan perangkat, dan fungsi keterhubungan kabel tersebut. Selanjutnya, ruang server pada data center sudah memiliki redundansi atau jalur ganda kabel backbone dan entrance area untuk tier 3. Jalur pertama melalui ruang entrance di dekat ruang operation center, dan jalur kedua melalui ruang entrance di dekat ruang storage \& loading dock. Terkait dokumentasi, perlu adanya penerapan dokumentasi dari pelabelan rak, kabel, perangkat yang sudah diterapkan, agar memudahkan penelusuran dalam melakukan troubleshooting dan maintenance.
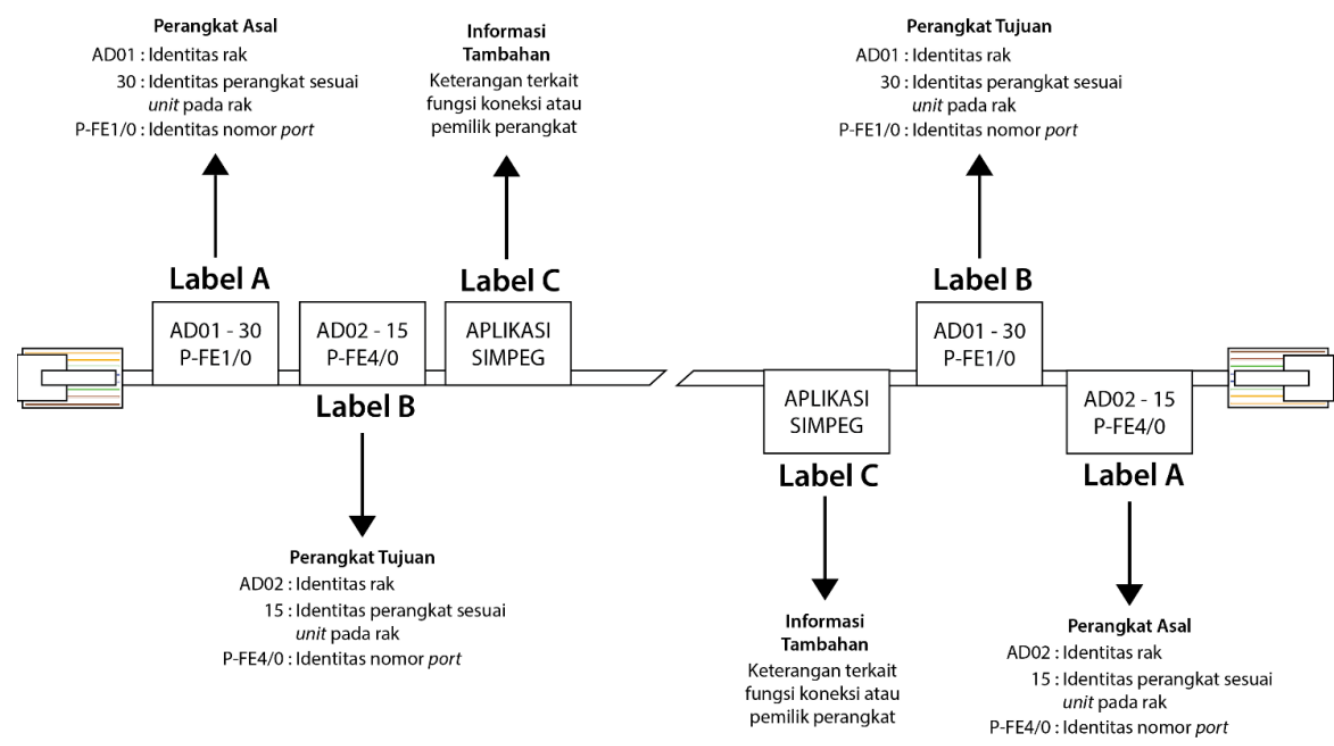

Gambar 9 Pelabelan pada kabel 


\section{DAFTAR PUSTAKA}

[1] K. Lee and K. Joshi, "Importance of Globalization in the Information," Global Information Technology Management, [9] 2016.

[2] H. Geng, "Data Centres-Strategic Planning, Design, [10] Construction, And Operations," in Data Center Handbook, Palo Alto, California: John Wiley \& Sons, Inc, 2015.

[3] D. S. Dewandaru and A. Bachtiar, "Perancangan Desain Ruangan Data Center Menggunakan Standar TIA-942 (Studi Kasus: Puslitbang Jalan Dan Jembatan)," Bandung, 2014.

[4] Pemerintah Kabupaten Bandung, "Tugas Pokok dan Fungsi DISKOMINFO PEMKAB BANDUNG," April 2017.

[Online]. Available: Lampiran 1 http://www.bandungkab.go.id/uploads/20170322110352tupoksi-diskominfo.pdf. [Accessed 24 Mei 2017].

Telecommunication Industry Association, Telecommunications Infrastructure Standard for Data Centers TIA-942-A, Revision Lampiran 3 of TIA-942 ed., Arlington, Virginia: Telecommunication Industry Association, 2012.
Lampiran 4

Telecommunications Pathways and Spaces TIA-569-C, Arlington, Virginia: Telecommunications Industry Association, 2012.

Uptime Institute, LLC, "Data Center Site Infrastructure Tier Standard: Topology," 2012.

S. Binus University, Library Binus University, 2014. [Online]. Available: http://library.binus.ac.id/eColls/eThesisdoc/Bab2/2014-200289-SK\%20Bab2001.pdf. [Accessed 30 Mei 2017].

[11] Cisco Systems .Inc, Designing Cisco Network Service Architectures, Student Guide ed., vol. 1, San Jose, California: Cisco Systems .Inc, 2007.

\section{LAMPIRAN}

Denah ruangan data center Pemerintah Kabupaten Bandung saat ini

Lampiran 2 Denah jalur kabel dan lampu pada data center Pemerintah Kabupaten Bandung

Denah ruangan usulan data center Pemerintah Kabupaten Bandung

Usulan denah data center tier 3 Pemerintah Kabupaten Bandung

[6] ADC Telecommunication .Inc, "TIA-942 Data Center Standards Overview," White Paper, 2008.

[7] C. Hendy, Secure Operation Data Center menurut TIA-942-A, Bandung: Institut Teknologi Bandung, 2016.

[8] Telecommunications Industry Association, 


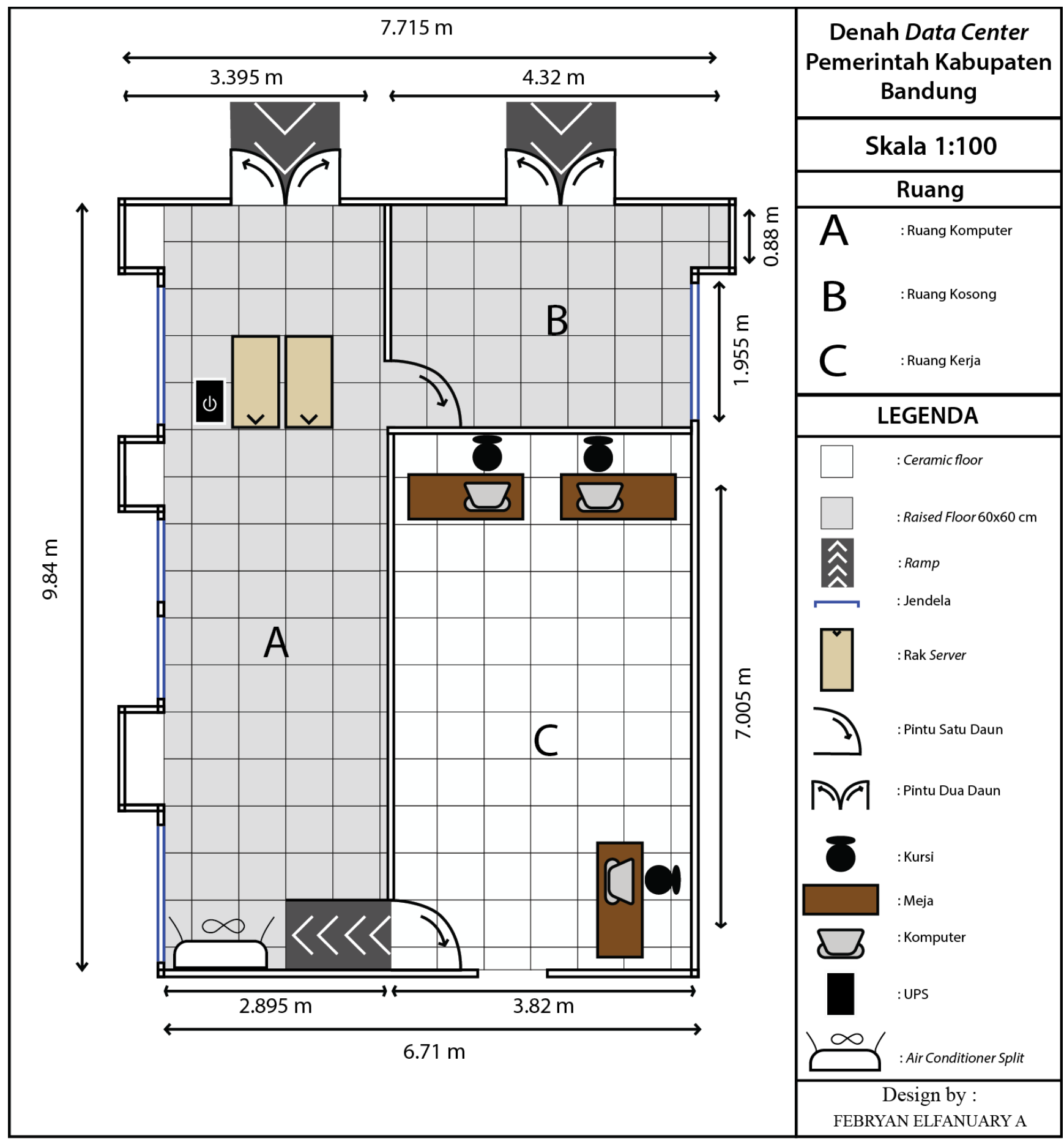

Lampiran 1 Denah ruangan data center Pemerintah Kabupaten Bandung saat ini 


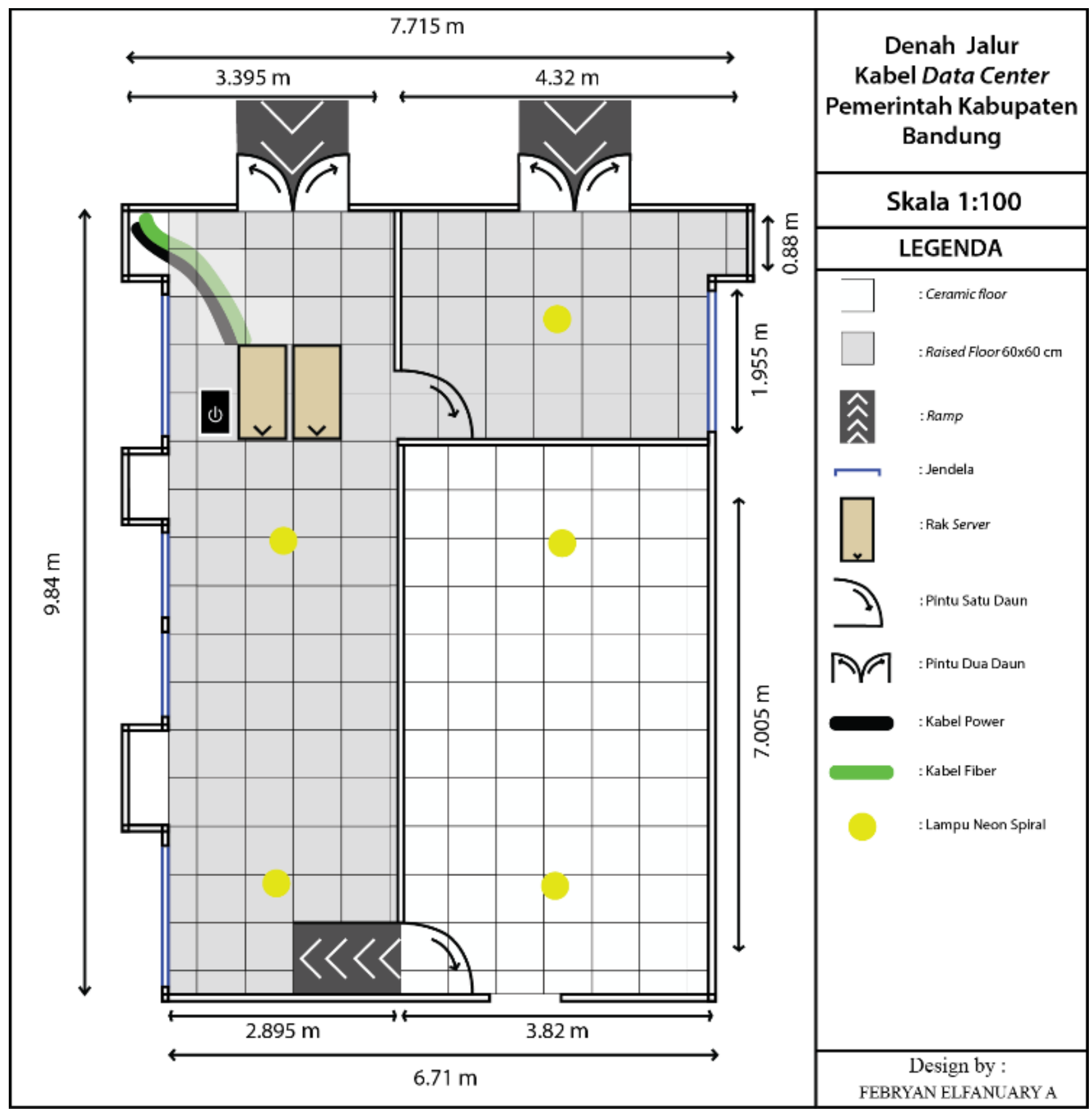

Lampiran 2 Denah jalur kabel dan lampu pada data center Pemerintah Kabupaten Bandung 


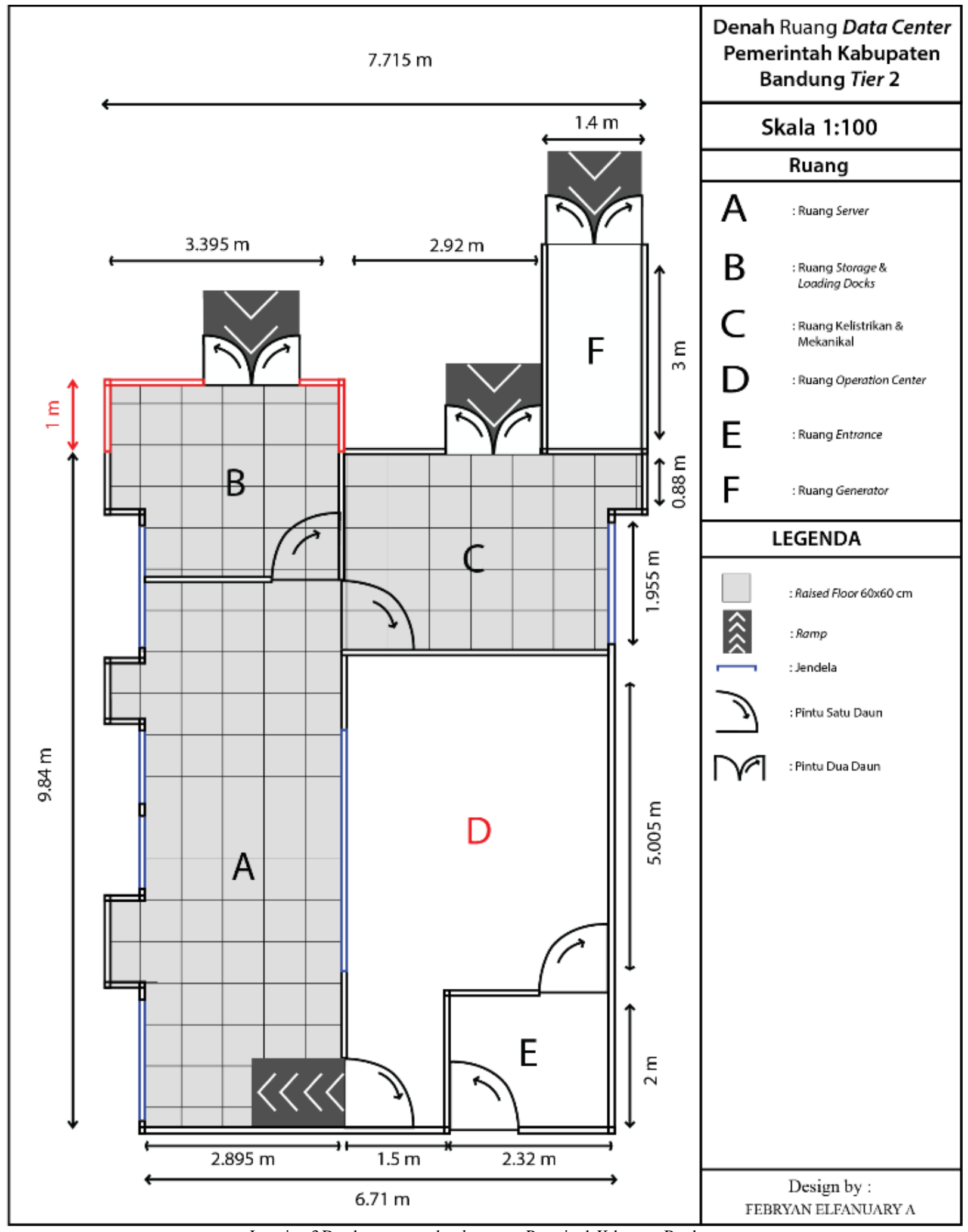

Lampiran 3 Denah ruangan usulan data center Pemerintah Kabupaten Bandung 


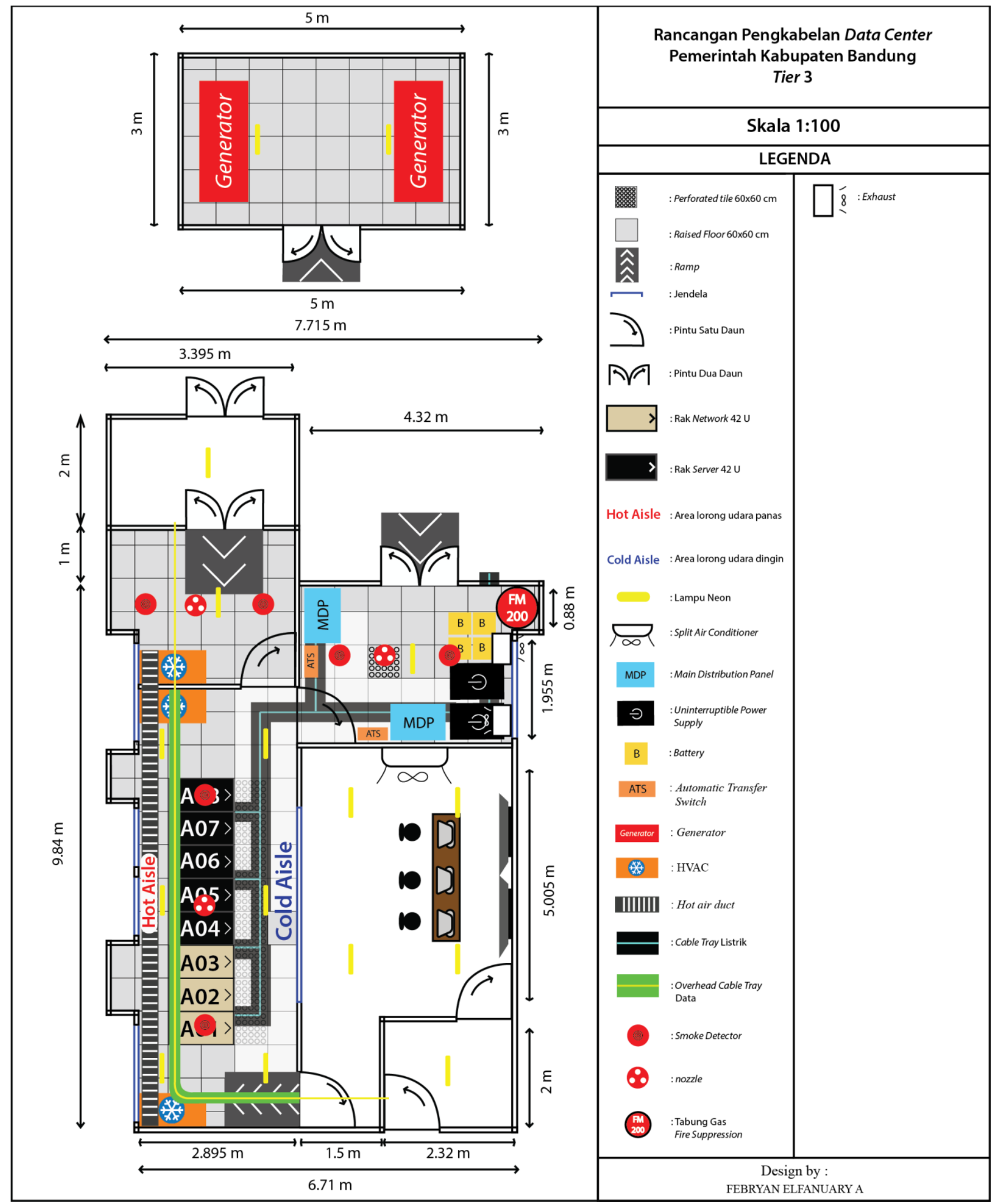

Lampiran 4 Usulan denah data center tier 3 Pemerintah Kabupaten Bandung 